\title{
Research on the Rockburst Tendency and AE Characteristics of Inhomogeneous Coal-Rock Combination Bodies
}

\author{
Yun-liang Tan, ${ }^{1,2}$ Wei-yao Guo, ${ }^{1,2}$ Qing-heng Gu, ${ }^{1,2}$ Tong-bin Zhao, ${ }^{1,2}$ Feng-hai Yu, ${ }^{1,2}$ \\ Shan-chao Hu, ${ }^{1,2}$ and Yan-chun Yin ${ }^{1,2}$ \\ ${ }^{1}$ State Key Laboratory of Mining Disaster Prevention and Control Co-Founded by Shandong Province and the Ministry of \\ Science and Technology, Shandong University of Science and Technology, Qingdao 266590, China \\ ${ }^{2}$ School of Mining and Safety Engineering, Shandong University of Science and Technology, Qingdao 266590, China
}

Correspondence should be addressed to Wei-yao Guo; 363216782@qq.com and Qing-heng Gu; 15610451523@163.com

Received 16 January 2016; Accepted 22 March 2016

Academic Editor: Shimin Liu

Copyright (c) 2016 Yun-liang Tan et al. This is an open access article distributed under the Creative Commons Attribution License, which permits unrestricted use, distribution, and reproduction in any medium, provided the original work is properly cited.

\begin{abstract}
In order to research the influence of homogeneity on the rockburst tendency and on AE characteristics of coal-rock combination body, uniaxial compressive tests of inhomogeneous coal-rock combination bodies obeyed by the Weibull distribution were simulated using particle flow code $\left(\mathrm{PFC}^{2 \mathrm{D}}\right)$. Macromechanical properties, energy evolution law, and AE characteristics were analyzed. The results show that (1) the elastic modulus homogeneity $m_{E}$ has an exponential relation with macroscopic modulus $E$, and the bonding strength homogeneity $m_{\sigma}$ has an exponential relation with uniaxial compressive strength $\sigma_{c}$; (2) the rockburst tendency of the coal-rock combination body will increase with the increase of $m_{E}$ or $m_{\sigma}$, and $m_{\sigma}$ is the leading factor influencing this tendency; and (3) both the change law of AE hits and lasting time in different periods of AE characteristics are influenced by $m_{\sigma}$, but $m_{E}$ just influences the lasting time. The more inhomogeneous the coal-rock combination body is, the shorter the lasting time in booming period of $\mathrm{AE}$ characteristics will be. This phenomenon can be used to predict the rockburst tendency of the coal-rock combination body.
\end{abstract}

\section{Introduction}

The geotechnical properties of rock associated with coal seams play a significant role in the design, operation, safety, and stability of both underground and open-cut mining operations $[1,2]$. In particular, for the combined structure composed of coal and rock mass, its stability directly reflects dynamic disaster dangers, such as roof fall, coal bump, and rockburst. In the process of deep coal resources exploitation, the engineering accidents and disasters often happen due to the instability and failure of coal and rock structure. In particular, coal-rock dynamic disasters can be easily induced when roof and floor suddenly lose stability in the process of coal mining $[3,4]$. Therefore, the interaction between the surrounding rock and coal is a key influencing factor in keeping the dynamic equilibrium of structure composed of roof, coal, and floor. In recent years, many researches focusing on coalrock combination bodies have been fruitfully conducted, and some outstanding achievements have been obtained and reported. For example, the research done by Qi et al. $[5,6]$ on different coal-rock combination bodies and the mechanism of rockburst reflected that employing coal-rock combination body to determine the tendency of rockburst was in more accordance with the actual underground conditions. Dou et al. [7-9] studied the rockburst tendency and precursor information of acoustoelectric effect, and the tests proved that coal-rock combination bodies could lose instability suddenly. Zuo et al. [10] found that the failure of combined coal-rock mass mainly occurred inside the coal, and the confining pressure, combination modes, and loading conditions play a very important role on the failure mode of combined samples. Petukhov and Linkov [11] analyzed the stability of general bipartite system and the roof-coal system when studying the stable behavior of rock mass after postpeak point. Vakili and Hebblewhite [12] developed a new cavability assessment criterion for top-coal embedded in combined coal-rock system composed of immediate roof, top coal, cutting coal, and floor by numerical modeling. Mohtarami et al. [13] 
studied the interaction between soil mass and downward rock blocks as a combined structure by a theoretical model for stability analysis.

Rock is a kind of porous medium material composed of mineral crystals different in size and shape, and these crystals are bonded together by cement. It is very inhomogeneous in the microstructure, which means that rock is inhomogeneous material. Researches [14-16] have shown that the inhomogeneity has an important effect on the failure patterns of rock since the inhomogeneity of rock influences its physical and mechanical properties and the crack generation and evolution law during the failure process of rock. Thus studying the influence of inhomogeneity on the properties of coal-rock combination body has both academic and engineering values. It is, however, really hard to complete the study of homogeneous degree's influence on the properties of coal-rock combination body through physical experiments. Numerical method has become an important optional choice for this research. Unfortunately, only few literatures refer to the simulation experiments on the rockburst tendency of inhomogeneous coal or rock [17], and the influence on the rockburst tendency and $\mathrm{AE}$ characteristics of coal-rock combination body were not further analyzed.

Particle flow method can reflect the microcharacteristics of rock and shows the mechanism problems of rock mechanics. It is an effective method to study the rock mechanics problems from the microscopic view. In this paper, particle flow software $\mathrm{PFC}^{2 \mathrm{D}}$ is used to simulate the macromechanical properties of inhomogeneous coal-rock combination bodies. In order to research the influence of homogeneity on the rockburst tendency and $\mathrm{AE}$ characteristics of coal-rock combination body, both energy evolution law and AE change law are analyzed during the failure process of coal-rock combination body under uniaxial compression tests.

\section{Particle Flow Model of Inhomogeneous Coal-Rock Combination Bodies}

\subsection{Inhomogeneous Simulation of Coal-Rock Combination} Body. Hudson and Fairhurst [18] emphasised that as the strength of rock is not an intrinsic property but the result of a stochastic chain reaction, the Weibull distribution is appropriate for describing the mechanical breakdown process. As a microscopic parameter setting method, it is widely used at present, especially for studying the inhomogeneity of rock. Its probability distribution function $P(x)$ and probability density function $f(x)$ are shown in formulas (1) and (2), respectively. Figure 1 shows probability density function curves of different $m$, when $x_{0}$ is 1 . From this figure, we can find that the larger the homogeneity $m$ is, the smaller the discreteness of microparameters is. This means that the properties of coal or rock will become more homogeneous:

$$
\begin{aligned}
& P(x)=1-\exp \left[-\left(\frac{x}{x_{0}}\right)^{m}\right], \\
& f(x)=\frac{m}{x_{0}}\left(\frac{x}{x_{0}}\right)^{m-1} e^{-\left(x / x_{0}\right)^{m}},
\end{aligned}
$$

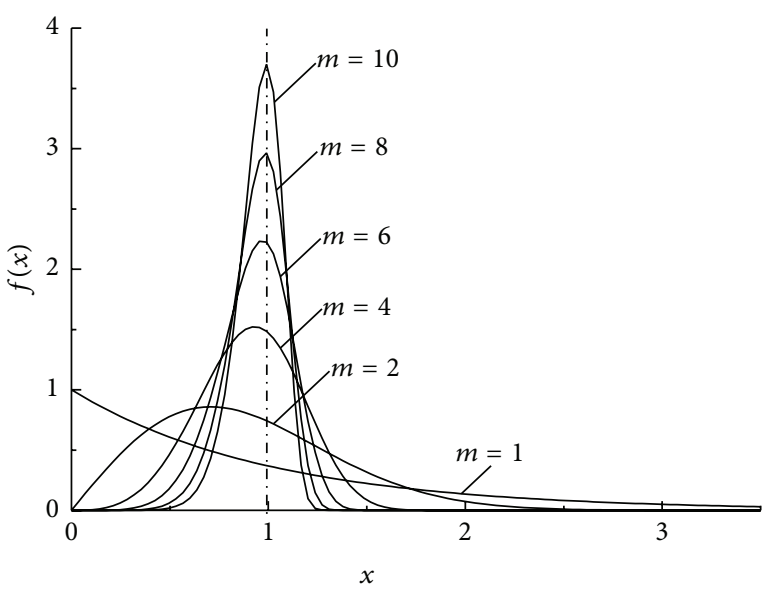

Figure 1: Curve of probability density of the Weibull distribution.

where $x_{0}$ is the value of expectation and $m$ is the value of homogeneity.

In particle flow code, particles are stiff. Particles are allowed to overlap each other for simulating the contact force between particles. There are two kinds of failure modes between particles, including shear failure and tension failure. $\mathrm{PFC}^{2 \mathrm{D}}$ has two different bonding models (contact bond and parallel bond) built into the code. Generally, contact bond is used to simulate granular materials such as soil, and parallel bond is used to simulate compact materials such as rock [19]. We choose the parallel bond in this paper. Two experiment schemes are designed. The first scheme is to keep the bonding strength $\sigma_{0}$ between coal particles $15 \mathrm{MPa}$ and the bonding strength $\sigma_{1}$ between rock particles $45 \mathrm{MPa}$, while the elastic modulus homogeneity $m_{E}$ between them is changed, with the desired values for coal and rock as $4 \mathrm{GPa}$ and $12 \mathrm{GPa}$, respectively. The second scheme is to keep the elastic modulus $E_{0}$ between coal particles $4 \mathrm{GPa}$ and the elastic modulus $E_{1}$ between rock particles $12 \mathrm{GPa}$, while the bonding strength homogeneity $m_{\sigma}$ between them is changed with the desired values for coal and rock as $15 \mathrm{MPa}$ and $45 \mathrm{MPa}$, respectively $\left(m_{E}\right.$ and $m_{\sigma}$ are short for elastic modulus homogeneity and bonding strength homogeneity later). Microparameters of coal and rock are shown in Table 1. The size of the model is $50 \times 100 \mathrm{~mm}^{2}$, and this model is created by radius expansion method. The loading rate is $0.01 \mathrm{~mm} / \mathrm{s}$, and the loading model is shown in Figure 2. In order to analyze the energy accumulation and release, the change of deformation energy is recorded during the loading process.

2.2. Index of Rockburst Tendency. The impact energy index $K_{E}$, elastic energy index $W_{E T}$, and dynamic failure time $D_{T}$ are often used for evaluating the rockburst tendency of coal. In this paper, the impact energy index $K_{E}$ is introduced to study the effect of inhomogeneous parameters on the rockburst tendency of coal-rock combination body. As shown in Figure 3, $K_{E}$ index refers to the ratio of the accumulative deformation energy $F_{s}$ before stress peak to the releasable deformation energy $F_{x}$ after stress peak under the condition of uniaxial compressive load. It reflects the 
TABLE 1: Microparameters of rock and mine.

\begin{tabular}{lcccccc}
\hline Materials & $\begin{array}{c}\text { Density } \\
\left(\mathrm{kg} / \mathrm{m}^{3}\right)\end{array}$ & $\begin{array}{c}\text { Radius } \\
(\mathrm{mm})\end{array}$ & $\begin{array}{c}\text { Friction } \\
\text { coefficient }\end{array}$ & $\begin{array}{c}\text { Radius of parallel } \\
\text { bond }(\mathrm{mm})\end{array}$ & $\begin{array}{c}\text { Elastic modulus } \\
(\mathrm{GPa})\end{array}$ & $\begin{array}{c}\text { Bonding strength } \\
(\mathrm{MPa})\end{array}$ \\
\hline Mine & 1800 & $0.2 \sim 0.3$ & 0.5 & 1 & 4 & 15 \\
Rock & 2600 & & & 12 & 12 & 45 \\
\hline
\end{tabular}

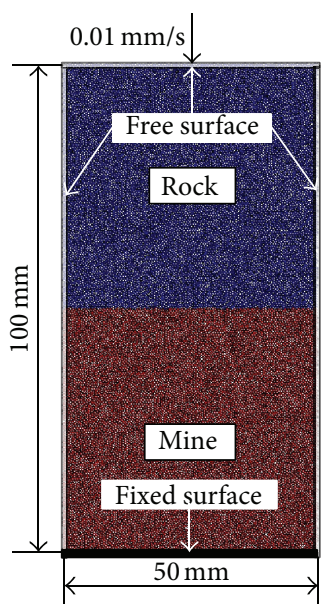

Figure 2: Test model.

energy transformation during the process of deformation and failure of coal-rock combination bodies. $K_{E}$ is defined in (3). Consider

$$
K_{E}=\frac{F_{s}}{F_{x}}
$$

where $F_{s}$ is the accumulative deformation energy before stress peak and $F_{x}$ is the releasable deformation energy after stress peak.

2.3. Numerical Experiment Mechanism of AE Phenomenon. $\mathrm{AE}$ events of rock are directly related to the generation of cracks, reflecting the crack formation of rock. AE is a good method for predicting rockburst $[20,21]$. In the parallel bonding model of $\mathrm{PFC}^{2 \mathrm{D}}$, the formation of each crack will generate an $\mathrm{AE}$ pulse, and $\mathrm{AE}$ events of coal-rock failure can be simulated and calculated by recording the number of cracks and post-processing of the data. During the process of uniaxial compressive tests, the time series characteristic curves of $\mathrm{AE}$ can be obtained by the above-mentioned method to research the influencing rule of inhomogeneous parameters on $\mathrm{AE}$ characteristics of coal-rock combination body.

\section{Homogeneity's Influence on the Rockburst Tendency of Coal-Rock Combination Body}

3.1. The Influence of Elastic Modulus Homogeneity. Stressstrain curves for coal-rock combination bodies of different elastic modulus homogeneity $m_{E}$ are shown in Figure 4. Figure 5 shows the relationship between macroelastic modulus $E$ and $m_{E}$. From Figure 4, we can find that $m_{E}$ influences

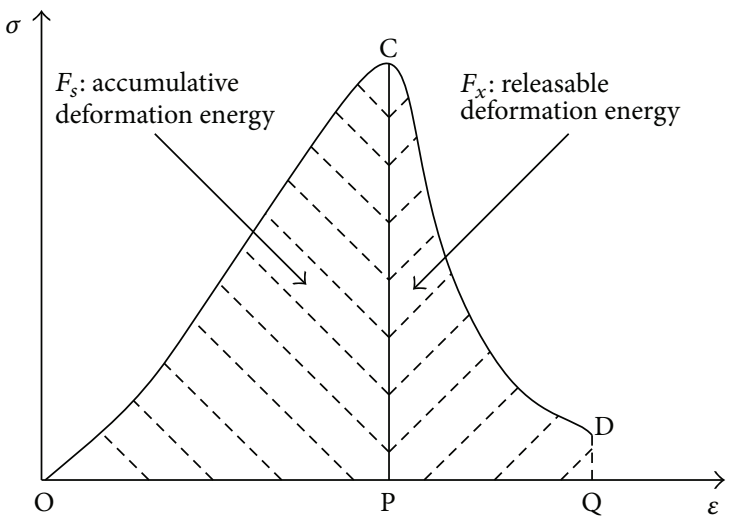

FIGURE 3: Calculation chart of $K_{E}$.

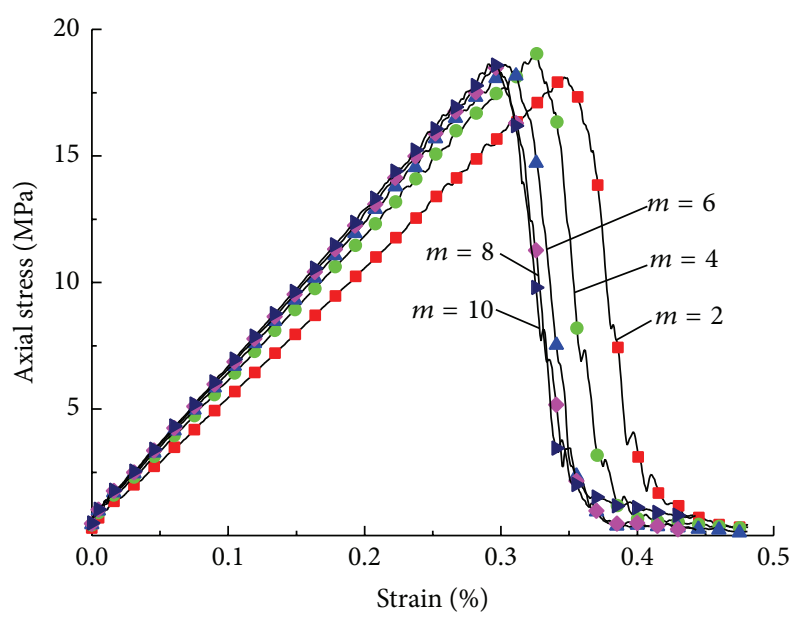

FIgURE 4: Stress-strain curves of different $m_{E}$.

the uniaxial compressive strength of coal-rock combination body little but mainly influences the strain during the failure process. The larger $m_{E}$ is, the lesser the strain is when the sample failure happens. The macroelastic modulus of coalrock combination body increases with the increase of $m_{E}$, while the growth rate decreases gradually. The relationship between them can be described through an exponential function, which is shown in formula (4). Consider

$$
E=6.13 \times 10^{9}-2.14 \times 10^{9} \times 0.675^{m_{E}} .
$$

The bonding rupture number of different $m_{E}$ during the loading process is shown in Figure 6. From Figure 6, we can see that $m_{E}$ has little influence on the total number of bonding ruptures or its generation because the bonding strength between particles is not changed, but it has an obvious influence on the time of crack evolution. The lesser 


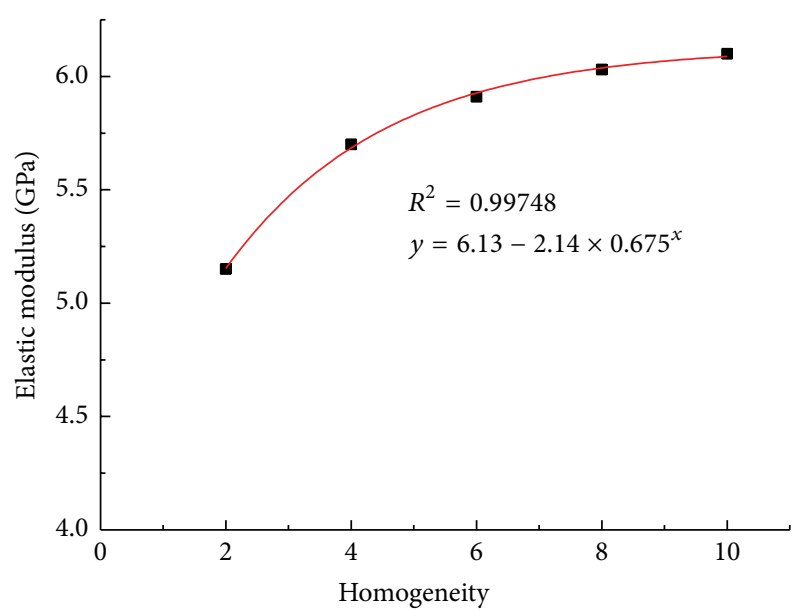

FIGURE 5: The relationship between elastic modulus and $m_{E}$.

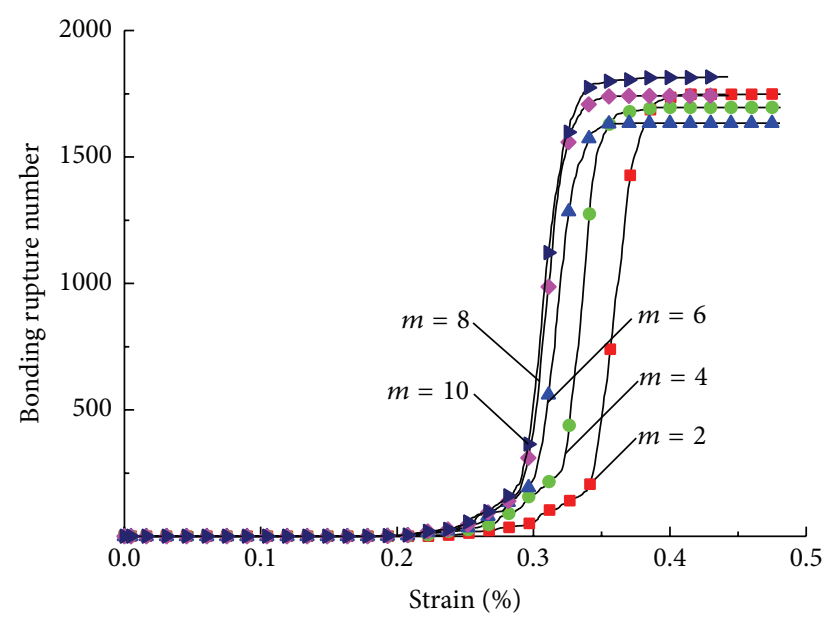

FIgURE 6: Bonding rupture number of different $m_{E}$.

$m_{E}$ is, the longer the time of crack evolution is. What is more, the failure modes of different $m_{E}$, which are mainly "V shape" shear failure of coal, are similar, as shown in Figure 7 (this figure only gives the failure mode of coal-rock combination body when $m_{E}$ is 2 , because their failure modes are similar).

Strain energy curves of different $m_{E}$ during the loading process are shown in Figure 8. This figure shows that when $m_{E}$ is small, the accumulative strain energy before the failure of coal-rock combination body is relatively low. With the increase of $m_{E}$, the accumulative strain energy increases gradually, while $m_{E}$ has little influence on the energy release after stress peak.

The relationship between impact energy index and $m_{E}$ is shown in Figure 9. The impact energy index of coal-rock combination body shows a gradual increase with the increase of $m_{E}$. The amplitude of variation is small. When $m_{E}$ increases from 2 to 10, impact energy index increases from 4.81 to 5.50 only by 0.14 times.

As a general view, the influence of $m_{E}$ on the failure modes and strength of coal-rock combination body is small, but the influence on the strain is large. When $m_{E}$ is small,

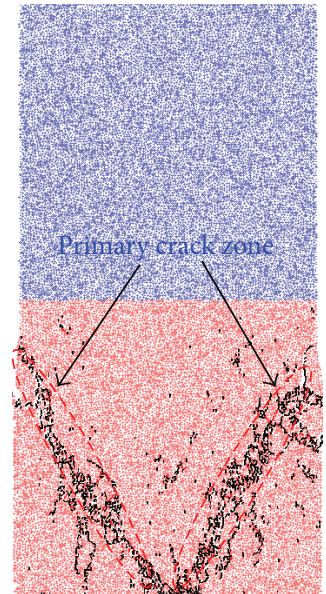

Figure 7: Failure mode of coal-rock combination body $\left(m_{E}=2\right)$.

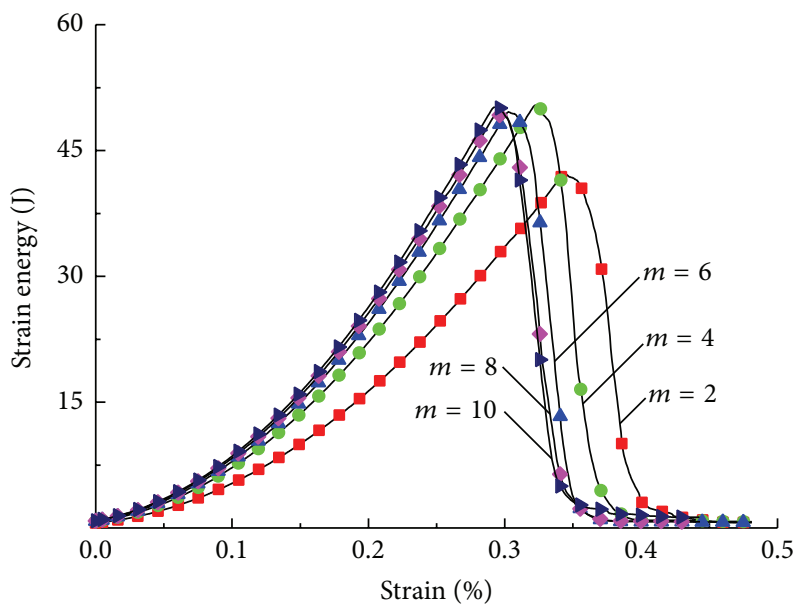

FIGURE 8: Energy curves of different $m_{E}$.

the difference of elastic modulus between particles is large, causing the coal and rock to be soft. During the loading process, the energy accumulates slowly. When the local stress exceeds the bonding strength between particles, crack generation happens, causing energy release. The release is abundant because of the long time of crack evolution. So the accumulative energy before the stress peak is small, and the rockburst tendency is weak. When $m_{E}$ is large, the difference of elastic modulus between particles is small, and the process for accumulating energy is fast. So the energy release before the failure of coal-rock combination body is little, which means that the accumulative energy before the peak stress is large. That is why the rockburst tendency will strengthen if $m_{E}$ is large.

3.2. The Influence of Bonding Strength Homogeneity. Stressstrain curves of coal-rock combination bodies for different bonding strength $m_{\sigma}$ are shown in Figure 10. Figure 11 shows the relationship between uniaxial compressive strength $\sigma_{c}$ and $m_{\sigma} . m_{\sigma}$ has little influence on the macroelastic modulus of coal-rock combination body, but a big influence on the 


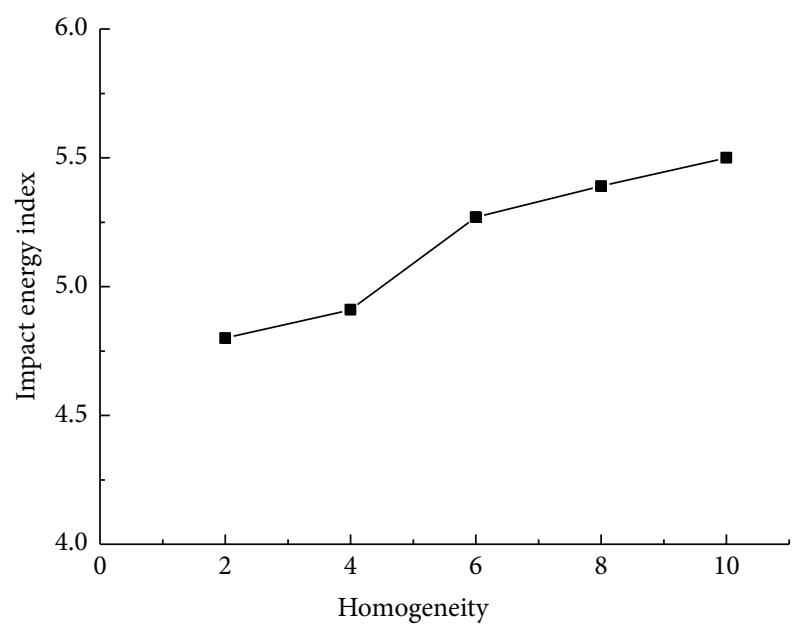

FIGURE 9: The relationship between impact energy index and $m_{E}$.

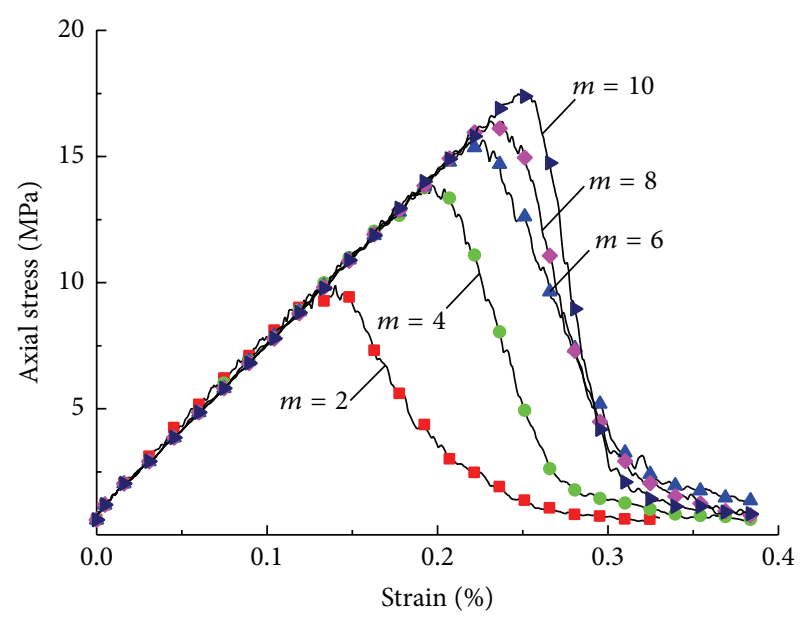

FIGURE 10: Stress-strain curves of different $m_{\sigma}$.

uniaxial compressive strength. The uniaxial compressive strength shows an increasing trend with the increase of $m_{\sigma}$, but its growth rate decreases. The relationship between them can be described by an exponential function, which is shown in formula (5). Consider

$$
\sigma_{c}=17.93 \times 10^{6}-14.84 \times 10^{6} \times 0.73^{m_{\sigma}} .
$$

The bonding rupture number of different $m_{\sigma}$ during the loading process is shown in Figure 12. The smaller $m_{\sigma}$ is, the longer the crack evolution time is, which will result in a larger number of bonding ruptures because of the great amount of particles of coal-rock combination body with low bonding strength under which cracks will generate, while the larger $m_{\sigma}$ is, the shorter the crack evolution time is, which will result in lesser number of bonding ruptures when the samples are broken, because the bonding strength between particles is large and crack generation needs high stress.

Failure modes of different $m_{\sigma}$ are shown in Figure 13. From Figure 13, "V shape" shear failure is found to be the main failure mode where $m_{\sigma}$ has an obvious effect on the distribution of microfissures. When $m_{\sigma}$ is small,

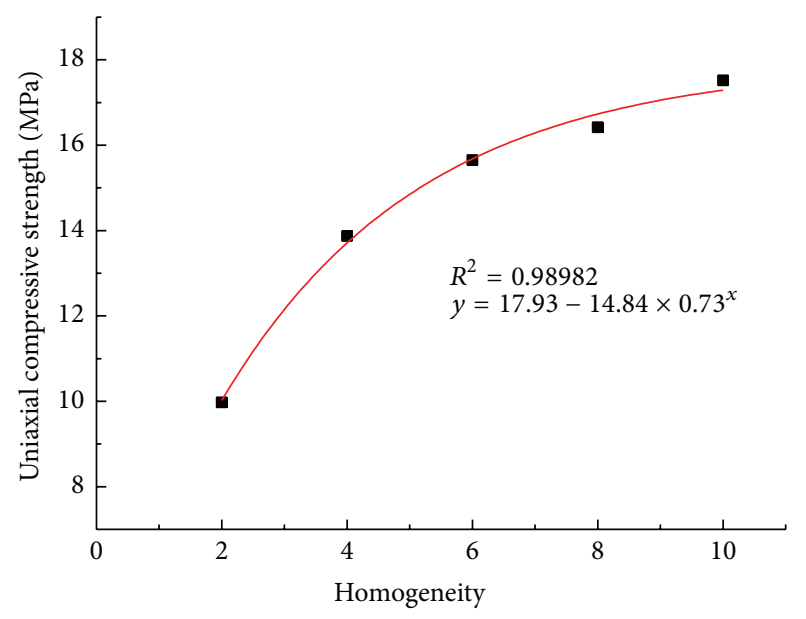

FIGURE 11: The relationship between uniaxial compressive strength and $m_{\sigma}$.

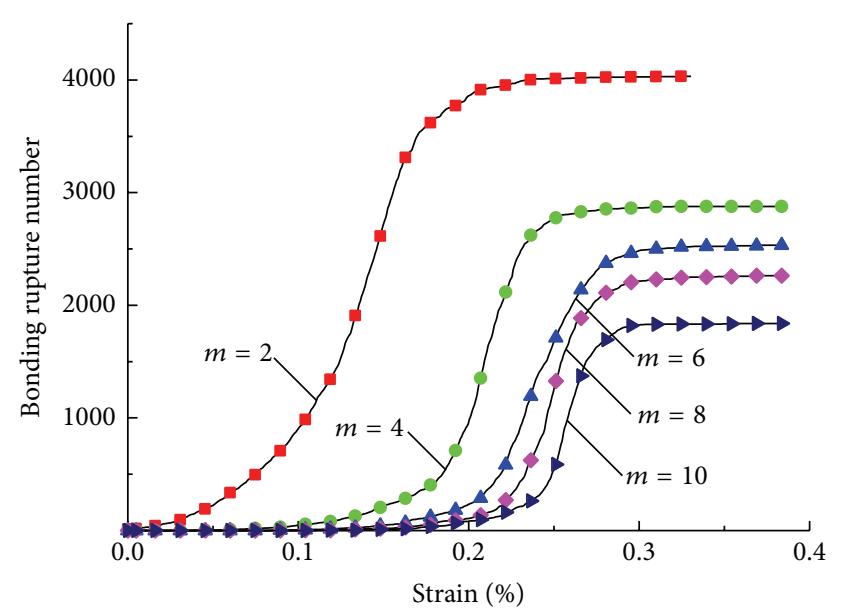

FIGURE 12: Bonding rupture number of different $m_{\sigma}$.

there are lots of microfissures distributing among the " $\mathrm{V}$ shape" shear zone. Both the randomness and discreteness of microfissures distribution are reduced with the increase of $m_{\sigma}$. What is more, these microfissures are gradually close to the "V shape" shear zone. Thus fissures localization is increasingly apparent, which means that the "V shape" shear zone becomes narrower.

Strain energy curves of different $m_{\sigma}$ during the loading process are shown in Figure 14. From the prepeak state of strain energy curves, it shows that the accumulative strain energy increases with the increase of $m_{\sigma}$. From the postpeak state, it shows that the energy is released faster and faster with the increase of $m_{\sigma}$, easily leading to rockburst.

The relationship between impact energy index and $m_{\sigma}$ is shown in Figure 15. When $m_{\sigma}$ increases, the impact energy index of coal-rock combination body will increase and the rockburst tendency will become more obvious. The impact energy index rises from 1.54 to 4.38 as $m_{\sigma}$ increases from 2 to 10 . Combined with the above research, it is evident that the influence of $m_{\sigma}$ on the rockburst tendency for coal-rock 


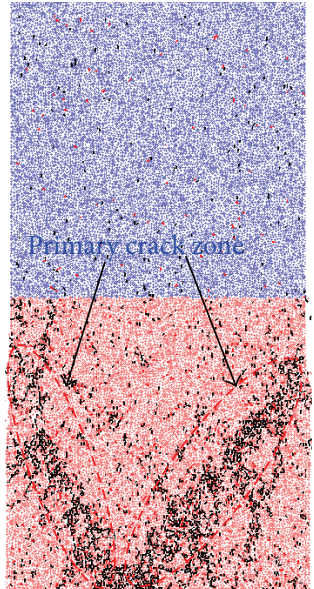

(a) $m_{\sigma}=2$

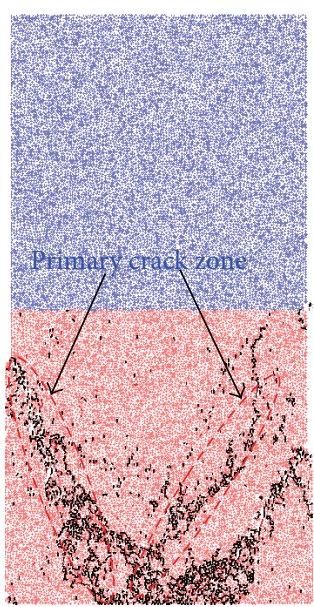

(c) $m_{\sigma}=6$

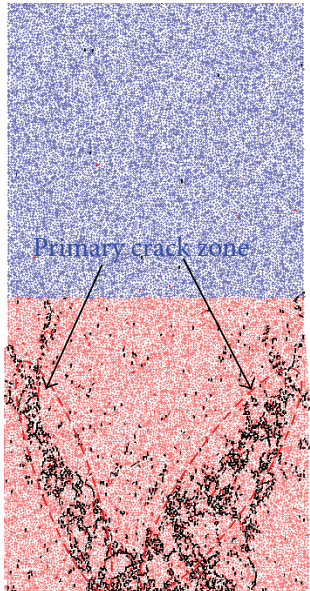

(b) $m_{\sigma}=4$

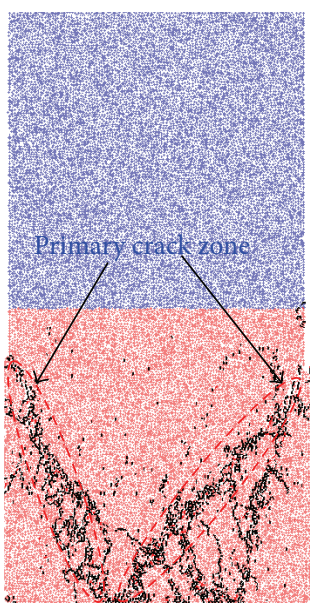

(d) $m_{\sigma}=8$

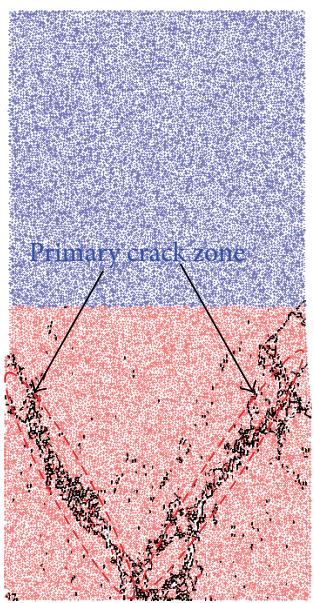

(e) $m_{\sigma}=10$

FIGURE 13: Failure modes of different $m_{\sigma}$.

combination body is stronger than that of $m_{E}$. So $m_{\sigma}$ is the key controlling factor.

In general, $m_{\sigma}$ has a strong influence on the failure modes and on the strength of coal-rock combination body.
Its influence, however, is small on the macroelastic modulus. When $m_{\sigma}$ is small, the number of particles with lower bonding strength is large. In the initial stage of loading, the bonding of particles begins to break under low strength. It 


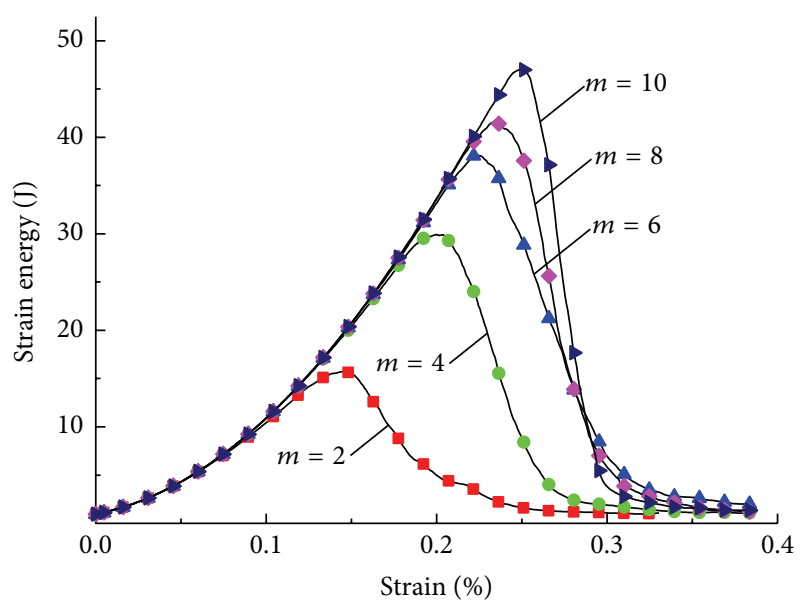

FIGURE 14: Energy curves of different $m_{\sigma}$.

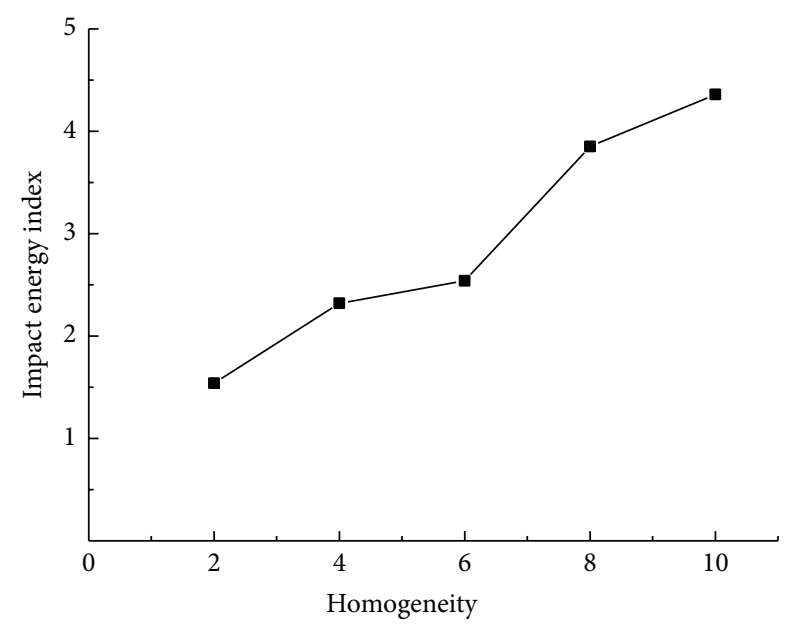

FIgURE 15: The relationship between impact energy index and $m_{\sigma}$.

will last in the whole loading process, and the time of crack evolution is long. The accumulative energy before the stress peak is small due to the energy release. Thus the rockburst tendency is weak. However, when $m_{\sigma}$ is large, the number of particles with higher bonding strength is high, the failure strength of coal-rock combination body is strong, and the time of crack evolution is short. The accumulative energy gets large and the rate of energy release goes fast. Therefore, the rockburst of coal-rock combination body is easy to happen.

\section{Homogeneity's Influence on AE Characteristics of Coal-Rock Combination Body}

4.1. The Influence of Elastic Modulus Homogeneity. The relationship between the number of $\mathrm{AE}$ hits and strain during the failure process of coal-rock combination bodies under different $m_{E}$ is shown in Figure 16. According to AE characteristics, the stress-strain curves can be generally divided into four stages: I: quiet period, II: developing period, III: booming period, and IV: dropping period. The influence of $m_{E}$ on the change law of AE hits is inapparent.

However, the duration times of AE characteristics under different $m_{E}$ are various. AE phenomenon has a direct connection with the internal crack generation of samples, but $m_{E}$ has little influence on the cracks' number. Thus, the influence of $m_{E}$ on the change law of $\mathrm{AE}$ hits in different stages is unobvious. $m_{E}$ influences the time of crack evolution greatly, causing lasting time under different $m_{E}$ in each stage different. For example, when $m_{E}$ increases from 2 to 10 , the total strain in I, quiet period, and II, developing period, decreases from $0.339 \%$ to $0.289 \%$ and the strain in III, booming period, from $0.071 \%$ to $0.062 \%$. This phenomenon implies that when $m_{E}$ increases, the rate of both energy accumulation and energy release will increase, manifesting the increasing possibility of rockburst.

4.2. The Influence of Bonding Strength Homogeneity. The relationship between the number of $\mathrm{AE}$ hits and strain during the failure process of coal-rock combination bodies under different $m_{\sigma}$ is shown in Figure 17. It is obviously shown that $m_{\sigma}$ has a significant influence on the wholeness law of $\mathrm{AE}$ characteristics. The change law of AE hits for coal-rock combination body can be described as follows:

(1) When $m_{\sigma}$ is small, the combination body will come into the II, developing period, directly without I, quiet period, and the number of AE hits keeps high. As the load increases, the number of $\mathrm{AE}$ hits will increase continuously. It will be at a high level in both the prepeaking strength and postpeaking strength.

(2) When $m_{\sigma}$ continues to increase, the combination body will come into the I, quiet period, during the initiating loading, which shows no AE phenomenon. With the increase of load, the number of AE hits shows an obviously increasing trend until it comes into the III, booming period. After that, it comes into $\mathrm{IV}$, dropping period, in which the number of AE hits decreases sharply.

(3) When $m_{\sigma}$ is high, AE phenomenon teems when near the III, booming period, whereas the number of $\mathrm{AE}$ hits is in a low level before that.

Above all, we can find that the AE characteristics of coalrock combination body can preferably reflect the change of $m_{\sigma}$.

In addition, the lasting time of I, quiet period, increases with the increase of $m_{\sigma}$. For instance, when $m_{\sigma}$ increases from 2 to 10 , the strain of coal-rock combination body during the I, quiet period, increases from 0 to $0.105 \%$. The duration of III, booming period, and peaking points of AE hits, however, shows a dropping tendency, such as the strain of coal-rock combination body during III, booming period, decreases from $0.043 \%$ to $0.026 \%$ as $m_{\sigma}$ changes from 2 to 10 . The reason is that the smaller $m_{\sigma}$ is, the longer the crack evolution time is. The phenomenon shows that $m_{\sigma}$ is the key factor influencing the change law of $\mathrm{AE}$ characteristics. It also implies that when $m_{\sigma}$ is larger, the accumulative energy will be larger and 


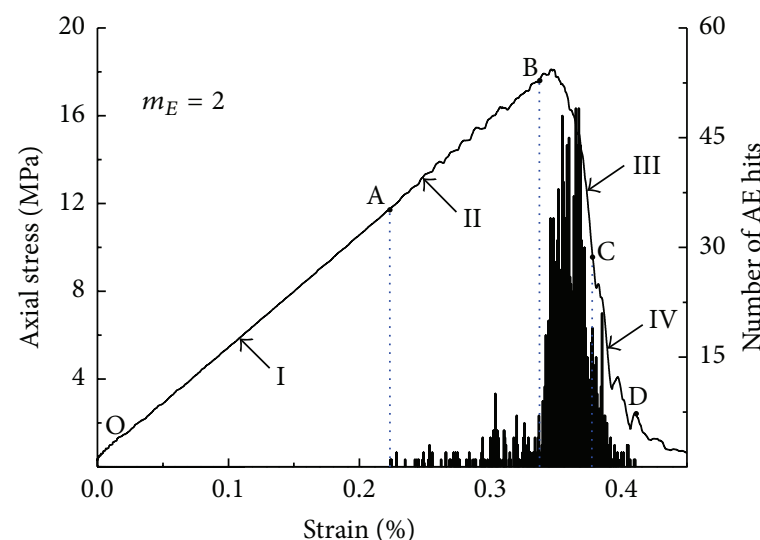

(a) $m_{E}=2$

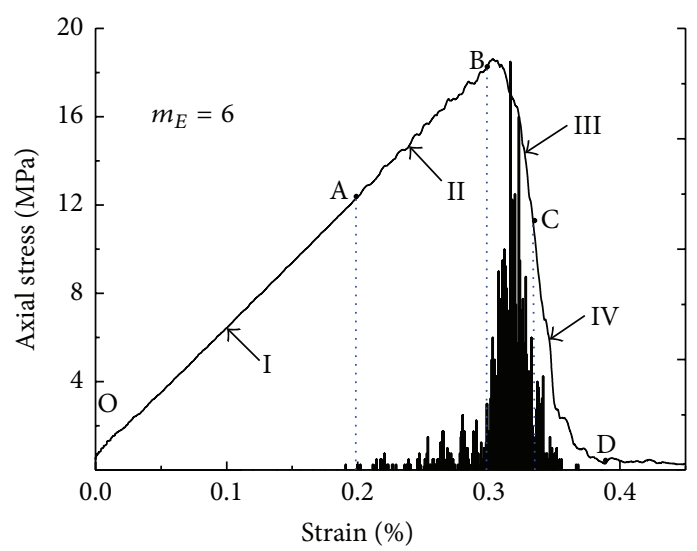

(c) $m_{E}=6$

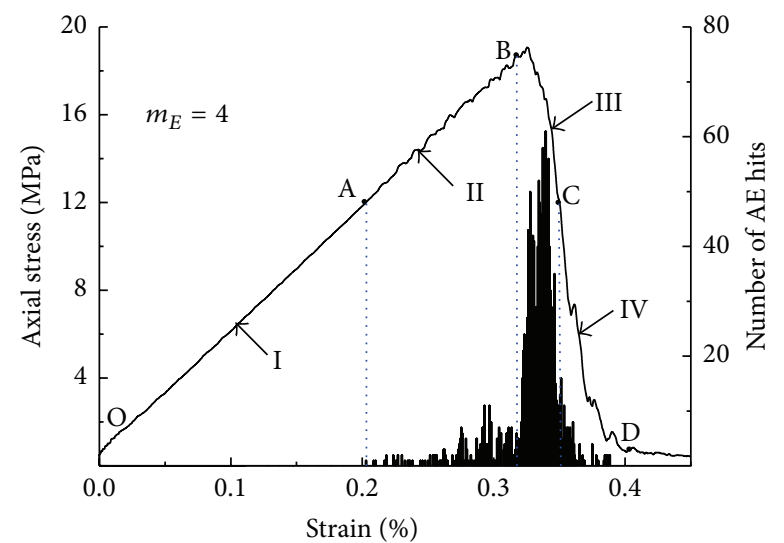

(b) $m_{E}=4$

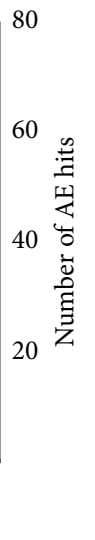

吾 16 (b) $m_{\mathrm{B}}=4$

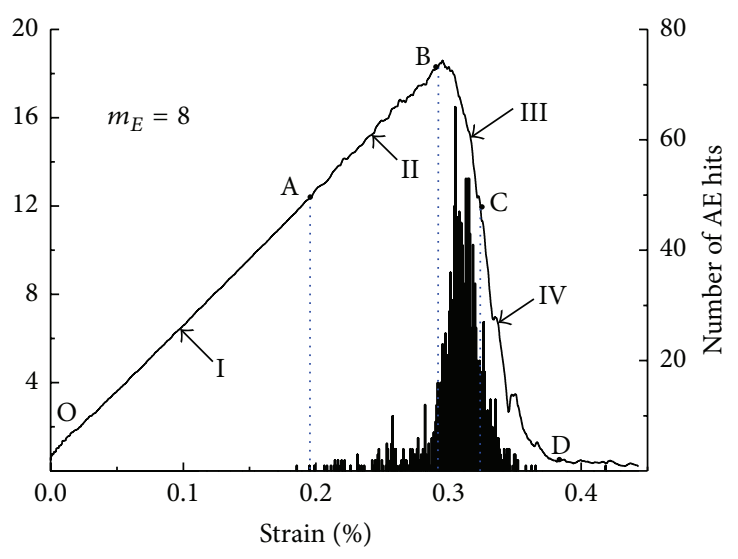

(d) $m_{E}=8$

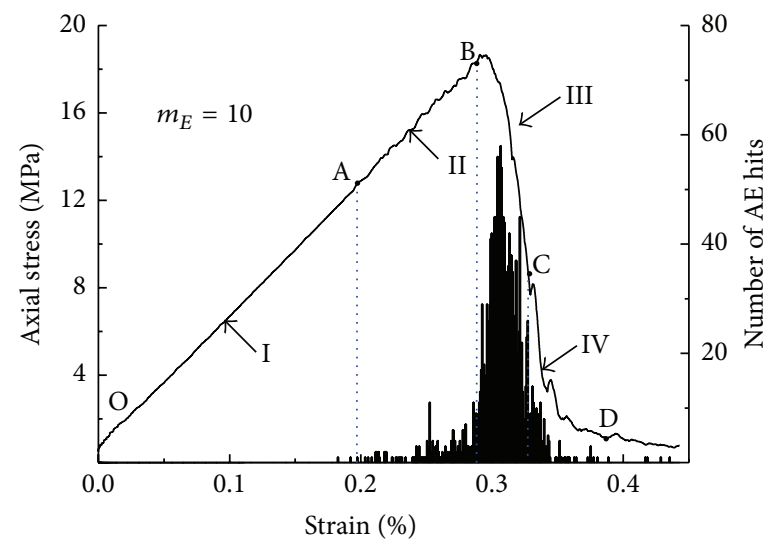

(e) $m_{E}=10$

Figure 16: AE curves of different $m_{E}$.

the rate of energy release will be faster. So the larger $m_{\sigma}$ is, the greater the possibility of rockburst will be.

\section{Discussing the Influence of Homogeneous Parameters}

Comparing the influence of the elastic modulus homogeneity $m_{E}$ and bonding strength homogeneity $m_{\sigma}$ on the rockburst tendency of coal-rock combination body, we know that the variable range of impact energy index influenced by
$m_{E}$ is $4.81 \sim 5.50$ and the range influenced by $m_{\sigma}$ is $1.51 \sim$ 4.38. Besides, $m_{\sigma}$ influences greater the rockburst tendency of coal-rock combination body compared to $m_{E}$. Elastic modulus is an elastic deformation parameter. On the one hand, it has a strong influence on the elastic deformation but only has an effect on the energy accumulation before the failure of samples. On the other hand, it has a weak effect on the plastic deformation and postpeak failure, resulting in the fact that that the energy release and crack generation of coal-rock combination body are 


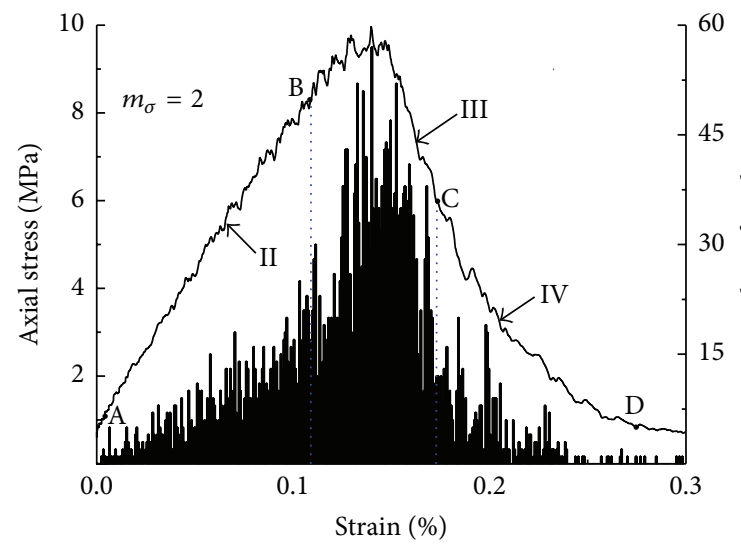

(a) $m_{\sigma}=2$

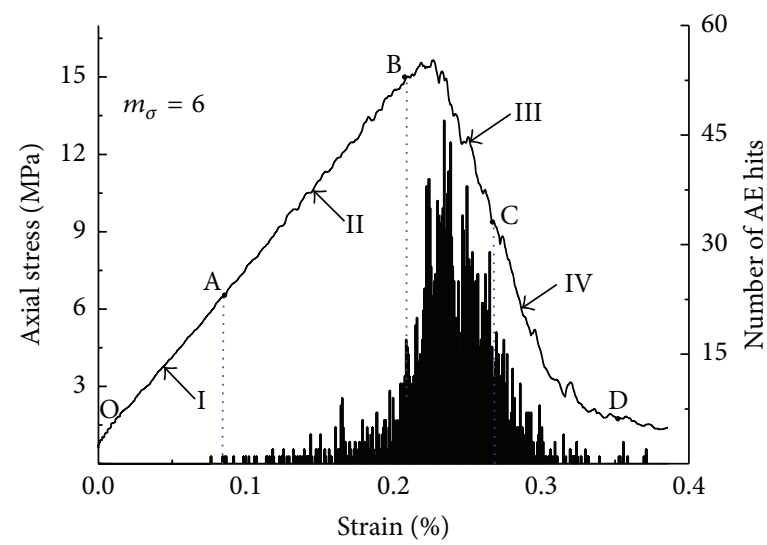

(c) $m_{\sigma}=6$

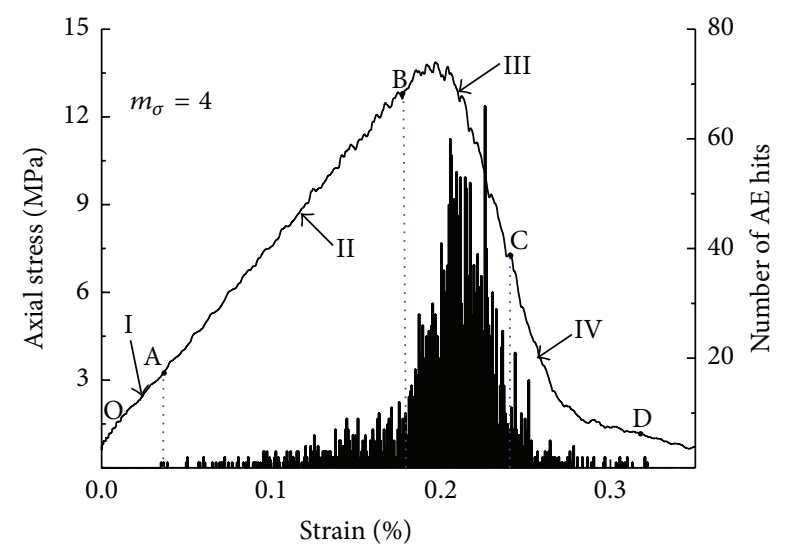

(b) $m_{\sigma}=4$

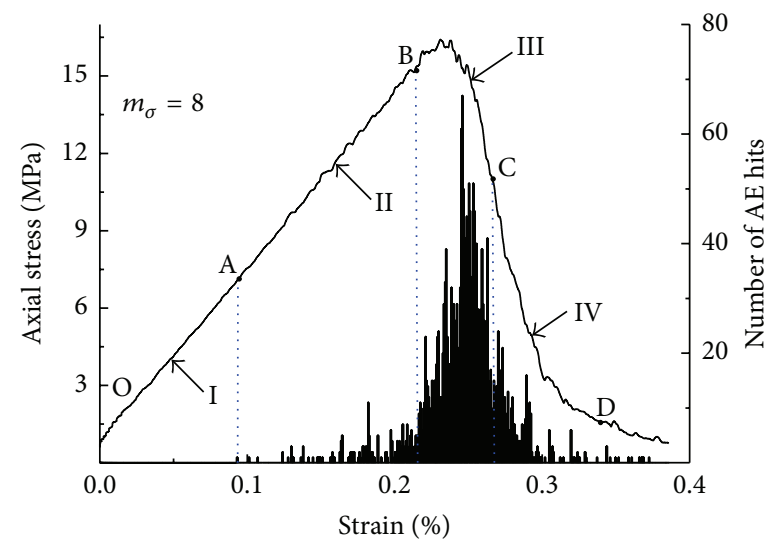

(d) $m_{\sigma}=8$

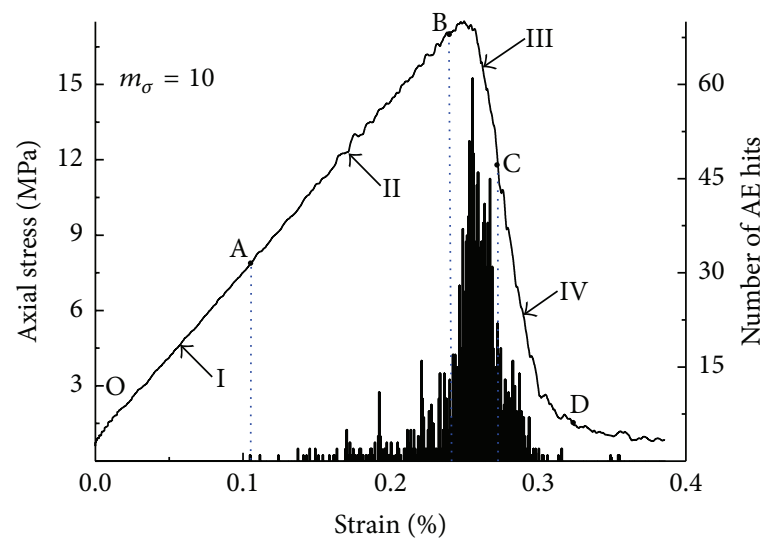

(e) $m_{\sigma}=10$

Figure 17: AE curves of different $m_{\sigma}$.

rarely influenced by $m_{E}$. Bonding strength mainly affects the failure process of coal-rock combination body. It controls the energy accumulation of prepeak strength, the energy release of postpeak strength, and the number of cracks. The AE phenomenon has a direct relation with the crack evolution law during the failure process of coal-rock combination body. Therefore, $m_{\sigma}$ has a great influence on the rockburst tendency and $\mathrm{AE}$ characteristics for coal-rock combination body.

\section{Conclusions}

From the above research on the influence of homogeneity on the rockburst tendency and AE characteristics of coal-rock combination body, the conclusions are as follows:

(1) The elastic modulus homogeneity $m_{E}$ has a weak influence on the failure modes and the strength of coal-rock combination body, and its macroelastic modulus shows an exponential function relation with 
$m_{E}$. The bonding strength homogeneity $m_{\sigma}$, however, has a little influence on the macroelastic modulus of the combination, and its uniaxial compressive strength shows an exponential function relation with $m_{\sigma}$.

(2) With the increase of elastic modulus homogeneity $m_{E}$ or bonding strength homogeneity $m_{\sigma}$, the possibility of rockburst tendency of coal-rock combination body will be enhanced. $m_{\sigma}$ plays a leading role in influencing the rockburst tendency. When $m_{\sigma}$ increases from to 2 to 10 , the impact energy index increases from 1.54 to 4.38 by 1.84 times while $m_{E}$ only increases by 0.14 times.

(3) The bonding strength homogeneity $m_{\sigma}$ has a strong influence on the wholeness law of AE characteristics, whereas the elastic modulus homogeneity $m_{E}$ only influences the lasting time of $\mathrm{AE}$ characteristics in each stages. $m_{\sigma}$ is the key factor influencing the change law of AE characteristics for coal-rock combination body. When $m_{E}$ increases, the lasting time of I, quiet period, II, developing period, and III, booming period, shows a slowly dropping trend; when $m_{\sigma}$ increases, the lasting time of I, quiet period, and II, developing period, increases but decreases during III, booming period.

(4) Combined with homogeneity's influence on the rockburst tendency and AE characteristics of coal-rock combination body, we can find that the larger the homogeneous degree is, the stronger the rockburst tendency will be, while the lasting time of III, booming period, will decrease with the increase of the homogeneous degree. This phenomenon has an important guiding significance for monitoring the rockburst.

\section{Competing Interests}

The authors declare that there are no competing interests regarding the publication of this paper.

\section{Acknowledgments}

The research described in this paper was financially supported by Natural Science Foundation of China (no. 51474136, no. 51474137, and no. 51274133), Doctoral Scientific Fund Project of the Ministry of Education of China (no. 20123718110013), Tai'shan Scholar Engineering Construction Fund of Shandong Province of China, and Qingdao Postdoctoral Applied Research project (no. 2015198).

\section{References}

[1] C. R. Ward, Ed., Coal Geology and Coal Technology, Blackwell Scientific Publications, Melbourne, Australia, 1984.

[2] L. Thomas, Coal Geology, John Wiley \& Sons, New York, NY, USA, 2002.
[3] Y. Tan, Y. Yin, S. Gu, and Z. Tian, "Multi-index monitoring and evaluation on rock burst in Yangcheng Mine," Shock and Vibration, vol. 2015, Article ID 624893, 5 pages, 2015.

[4] Y.-L. Tan, J.-G. Ning, T.-B. Zhao et al., Deformation and Control of Deep Roadways, Coal Industry Press, Beijing, China, 2011.

[5] Q.-X. Qi and L.-M. Dou, Theory and Technology of Rock Burs, China Mining University Press, Xuzhou, China, 2008.

[6] J.-X. Liu, C.-A. Tang, W.-C. Zhu et al., "Rock-coal model for studying the rockburst," Chinese Jounal of Geotechnical Engineering, vol. 26, no. 2, pp. 276-280, 2004.

[7] L.-M. Dou, J.-C. Tian, C.-P. Lu et al., "Research on electromagnetic radiation rules of composed coal-rock burst failure," Chinese Journal of Rock Mechanics and Engineering, vol. 24, no. 19, pp. 3541-3544, 2005.

[8] C.-P. Lu, L.-M. Dou, and X.-G. Wu, "Experimental research on rules of rockburst tendency evolution and acousticelectromagnetic effects of compound coal-rock samples," Chinese Journal of Rock Mechanics and Engineering, vol. 26, no. 12, pp. 2549-2555, 2007.

[9] Y.-X. Zhao, Y.-D. Jiang, J. Zhu, and G.-Z. Sun, "Experimental study on precursory information of deformations of coal-rock composite samples before failure," Chinese Journal of Rock Mechanics and Engineering, vol. 27, no. 2, pp. 339-346, 2008.

[10] J.-P. Zuo, Z.-F. Wang, H.-W. Zhou, J.-L. Pei, and J.-F. Liu, "Failure behavior of a rock-coal-rock combined body with a weak coal interlayer," International Journal of Mining Science and Technology, vol. 23, no. 6, pp. 907-912, 2013.

[11] I. M. Petukhov and A. M. Linkov, "The theory of post-failure deformations and the problem of stability in rock mechanics," International Journal of Rock Mechanics and Mining Sciences \& Geomechanics Abstracts, vol. 16, no. 2, pp. 57-76, 1979.

[12] A. Vakili and B. K. Hebblewhite, "A new cavability assessment criterion for longwall top coal caving," International Journal of Rock Mechanics \& Mining Sciences, vol. 47, no. 8, pp. 1317-1329, 2010.

[13] E. Mohtarami, A. Jafari, and M. Amini, "Stability analysis of slopes against combined circular-toppling failure," International Journal of Rock Mechanics and Mining Sciences, vol. 67, pp. 43$56,2014$.

[14] S. C. Yuan and J. P. Harrison, "A review of the state of the art in modelling progressive mechanical breakdown and associated fluid flow in intact heterogeneous rocks," International Journal of Rock Mechanics and Mining Sciences, vol. 43, no. 7, pp. 1001$1022,2006$.

[15] Y.-L. Tan, D.-M. Huang, and Z. Zhang, "Rock mechanical property influenced by inhomogeneity," Advances in Materials Science and Engineering, vol. 2012, Article ID 418729, 9 pages, 2012.

[16] Y.-L. Tan, Y.-C. Yin, and D. Huang, "Inhomogeneous microstructure influence on macro-crack of sandstone," Journal of Testing and Evaluation, vol. 41, no. 6, pp. 1024-1031, 2013.

[17] T.-B. Zhao, Y.-C. Yin, Y.-L. Tan, P. Wei, and J.-C. Zou, "Bursting liability of coal research of heterogeneous coal based on particle flow microscopic test," Journal of the China Coal Society, vol. 39, no. 2, pp. 280-285, 2014.

[18] J. A. Hudson and C. Fairhurst, “Tensile strength, Weibull's theory and a general statistical approach to rock failure. Structure, solid mechanics and engineering design," in The Proceedings of the Southampton 1969 Civil Engineering Materials Conference, M. Te’eni, Ed., pp. 901-914, 1969. 
[19] Y.-C. Yin, T.-B. Zhao, Y.-L. Tan et al., "Research of stress distribution evolution law and influencing factors," Journal of Mining \& Safety Engineering, vol. 30, no. 5, pp. 712-716, 2013.

[20] Y.-L. Tan, Z. Zhang, and T.-B. Zhao, "AE pattern of rock burst disaster induced by strata activation in coal mine," Disaster Advances, vol. 4, no. 4, pp. 29-33, 2011.

[21] Y.-L. Tan, F.-C. Li, H. Zhou, and X.-J. Han, "Analysis on acoustic emission pattern for rock burst," Chinese Journal of Rock Mechanics and Engineering, vol. 19, no. 4, pp. 425-428, 2000. 


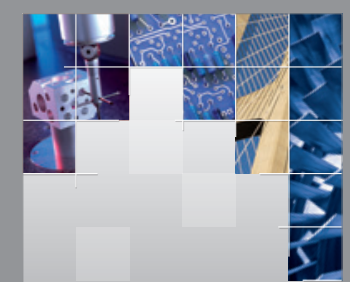

\section{Enfincering}
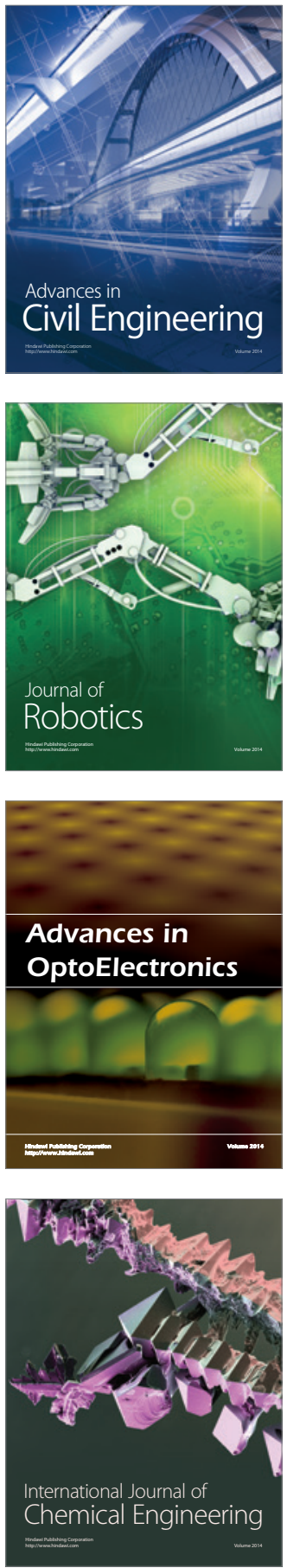

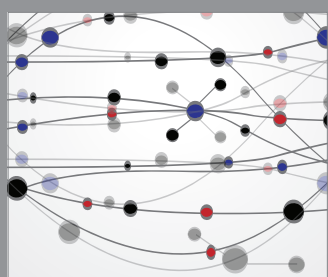

The Scientific World Journal

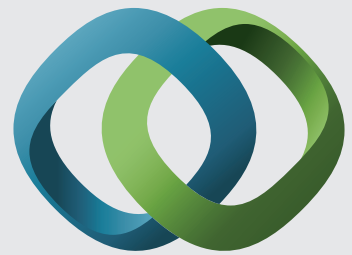

\section{Hindawi}

Submit your manuscripts at

http://www.hindawi.com
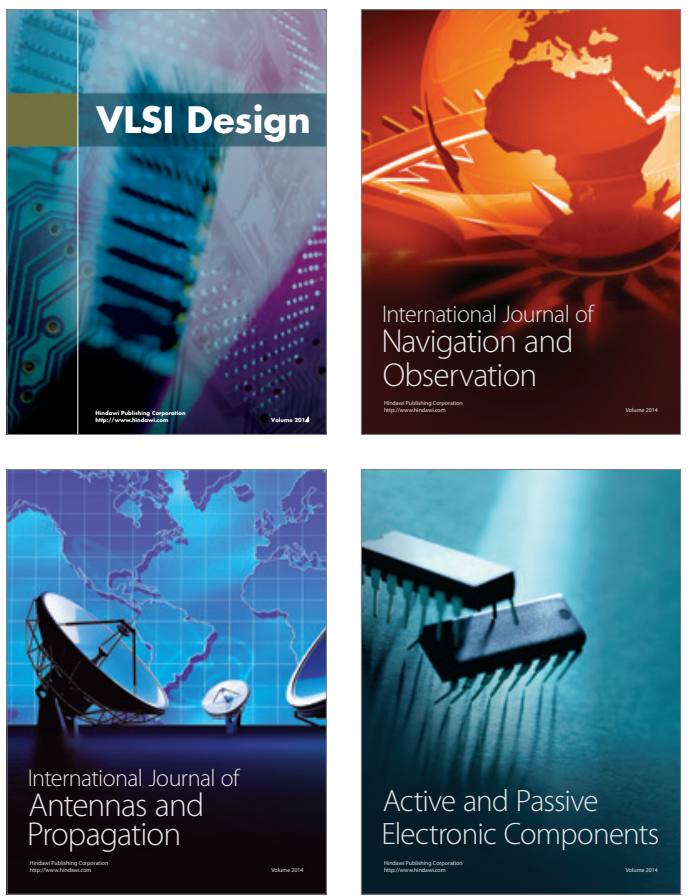
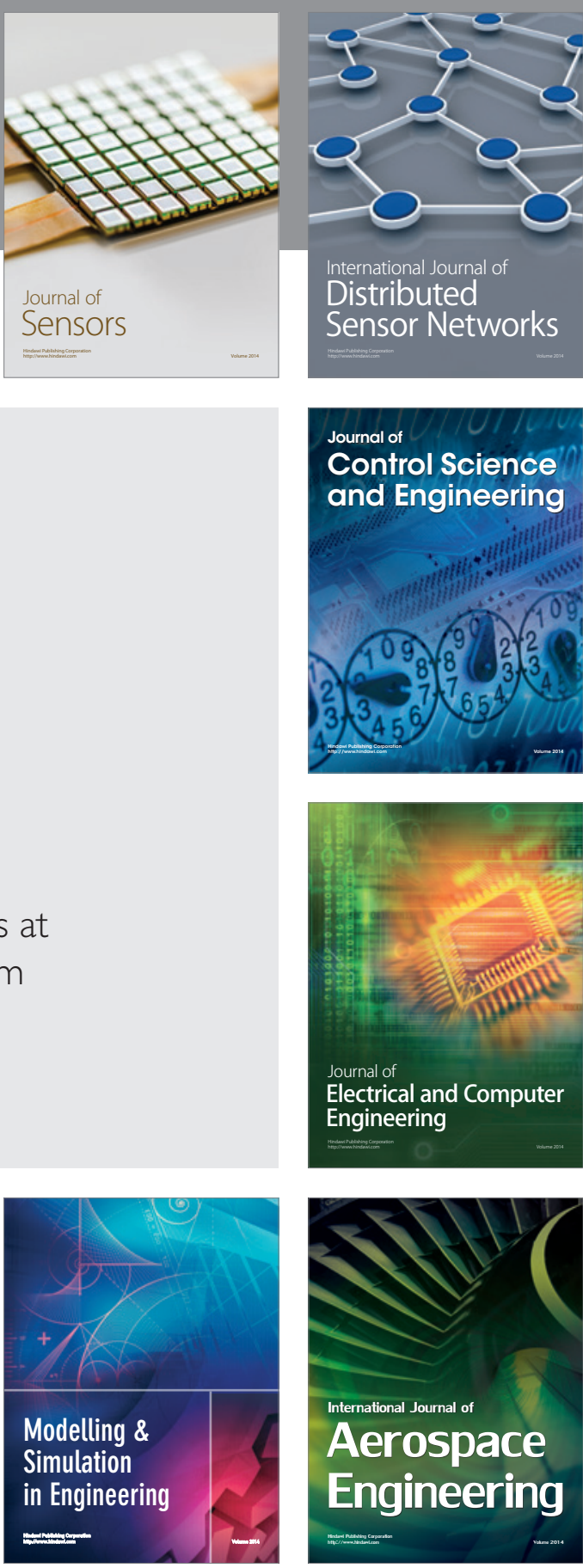

International Journal of

Distributed

Sensor Networks

Journal of

Control Science

and Engineering
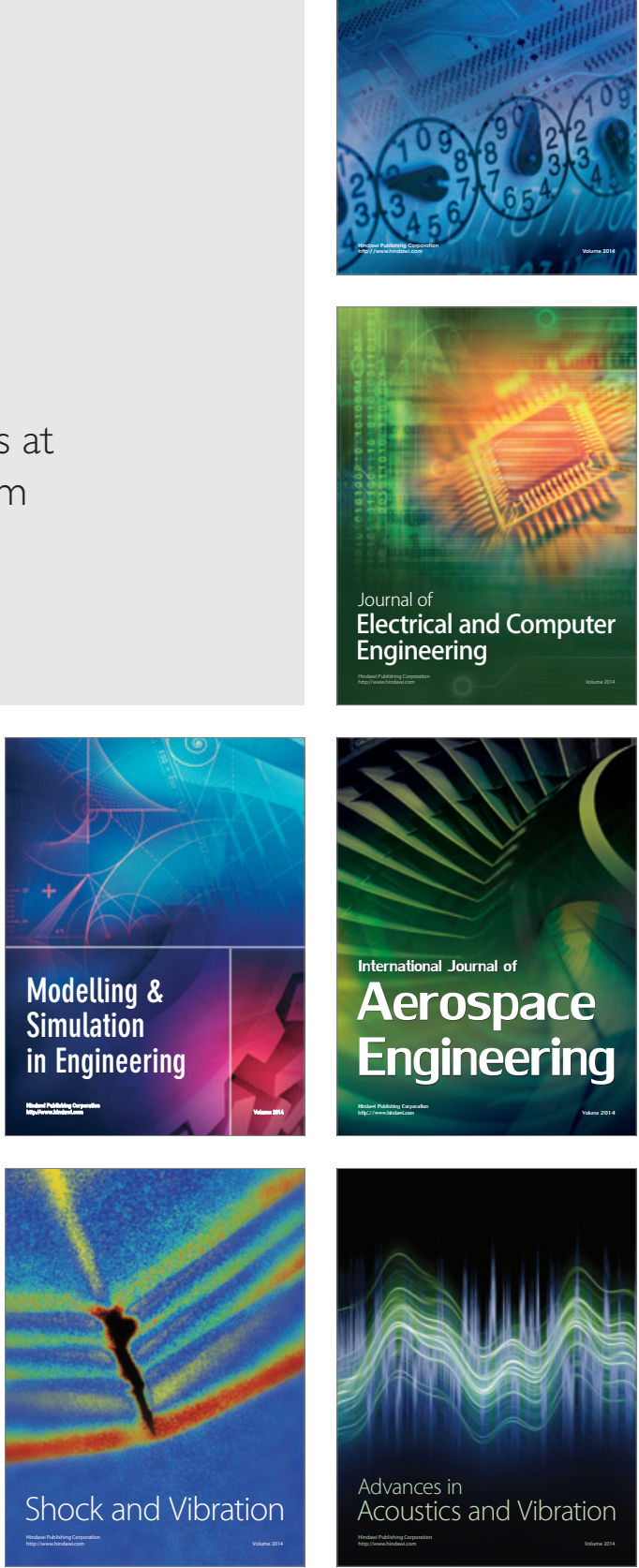